\title{
Internal Reactions of Ion-Neutral Complexes from some Disubstituted Protonated Benzaldehydes and Acetophenones
}

\author{
Hans-Fr. Grützmacher $†$ and Gerhard Thielking
}

Fakultät für Chemie, Universität Bielefeld, Universitätsstraße, D-4800 Bielefeld, FRG

\begin{abstract}
Protonated benzaldehydes 'a' and protonated acetophenones 'b', substituted by a methoxymethyl group, a hydroxymethyl group and a mercaptomethyl group, respectively, in position 3, in addition to a methoxymethyl side chain at position 5, have been prepared by electron impact induced dissociation from the corresponding benzylic alcohols. The spontaneous fragmentations of metastable ions of ' $a$ ' and ' $b$ ' have been investigated with the aid of specifically deuterated derivatives. Large signals are observed for the loss of methanol induced by a proton migration across the aromatic ring. The competing loss of $\mathrm{H}_{2} \mathrm{O}$ and $\mathrm{H}_{2} \mathrm{~S}$, respectively, from the second side chain is less abundant, in agreement with the smaller PA's of $\mathrm{HO}-$ and $\mathrm{HS}-$ groups. The elimination of $\mathrm{HCOX}$ and $\mathrm{CH}_{3} \mathrm{COX}(\mathrm{X}=$ $\left.\mathrm{OCH}_{3}, \mathrm{OH}, \mathrm{SH}\right)$, respectively, from ' $a$ ' and ' $b$ ' is also observed. The label distributions for these reactions are in agreement with a mechanism corresponding to an internal reaction of $\left[\mathrm{CHO}^{+}\right.$and $\left[\mathrm{CH}_{3} \mathrm{CO}^{+}\right.$, respectively, with the functional group of the side chains in an intermediary ion-neutral complex. In addition, fragmentations are observed arising from reactions between the two side chains at positions 3 and 5 . The $D$ labelling proves specific reactions without any $H / D$ exchange and thus reaction channels separated from the methanol loss. The results are explained by internal ion-molecule reactions in an intermediary ion-neutral complex of a methoxymethyl cation, a hydroxymethyl cation and a mercaptomethyl cation, respectively, formed by a protolytic bond cleavage of the side chains.
\end{abstract}

\section{INTRODUCTION}

Recently we have shown ${ }^{1}$ that protonated aromatic aldehydes and ketones, carrying a methoxymethyl group as the second side chain, fragment spontaneously in the 2nd field-free region (2nd FFR) of a VG ZAB-2F mass spectrometer by internal reactions within intermediary ion-neutral complexes. These fragmentations are initiated by a proton transfer from the protonated car-

$\dagger$ Author to whom correspondence should be addressed. bonyl group onto the aromatic ring, followed by a protolytic cleavage of the bond to either of the two substituents, forming two ion-neutral complexes (Scheme 1).

The complex formed by the acylium ion $[\mathrm{RCO}]^{+}$and the benzyl methyl ether fragments by the loss of an ester molecule $\mathrm{RCOOCH}_{3}$, while a typical reaction of the complex arising from the methoxymethyl cation and the aromatic ketone is an internal methylation of the ketone and the elimination of formaldehyde, $\mathrm{CH}_{2} \mathrm{O}$.

Intermediary ion-neutral complexes have been firmly established as important intermediates of unimolecular mass spectrometric fragmentations., ${ }^{2,3}$ The incipient



Scheme 1. Formation of ion-neutral complexes from protonated aromatic carbonyl compounds. 
cation is captured during these fragmentations by the neutral fragment by ion-dipole and ion-induced dipole forces, and if the internal energy of the system is low, the lifetime of the intermediary ion-neutral complex is long enough for a reorientation of its components. This enables an internal ion-neutral reaction even between rather remote groups. If the products of this internal reaction are thermochemically more stable than the original components, a fragmentation by this new route is observed instead of a direct dissociation of the ionneutral complex, at least for metastable ions.

The reaction shown in Scheme 1 confirms the expectation, that the fragmentations of metastable aromatic ions are especially prone to effects of intermediary ionneutral complexes because of the large polarizability of the aromatic $\pi$-electron system. Interestingly, these fragmentations correspond to the migration of a carbenium ion over rather large molecular distances within the complex, and a close analogy to bimolecular ionneutral processes ${ }^{4}$ is observed. The intermediary ionneutral complex of a unimolecular fragmentation corresponds to a very intimate reaction complex of the bimolecular process, and a study of the fragmentations mediated by ion-neutral complexes may give some information about proximity effects within such complexes. The internal processes hitherto observed correspond to reactions of an acylium ion with an ether group and to reactions of a methoxymethyl cation with a carbonyl group. An extension of the system can be achieved by the attachment of another side chain to the aromatic group, which affords a second reaction centre for the ionic component of the complex to study chemoselectivity within the ion-neutral complex. Furthermore, the protolytic bond cleavage of this side chain can give rise to a new complex. In this paper we present the first results of such a study, ${ }^{5}$ the additional side chain being a second methoxymethyl group, a hydroxymethyl group and a mercaptomethyl group, respectively.

\section{RESULTS AND DISCUSSION}

The most convenient method of generating protonated benzaldehydes ' $a$ ' and acetophenones ' $b$ ' substituted in

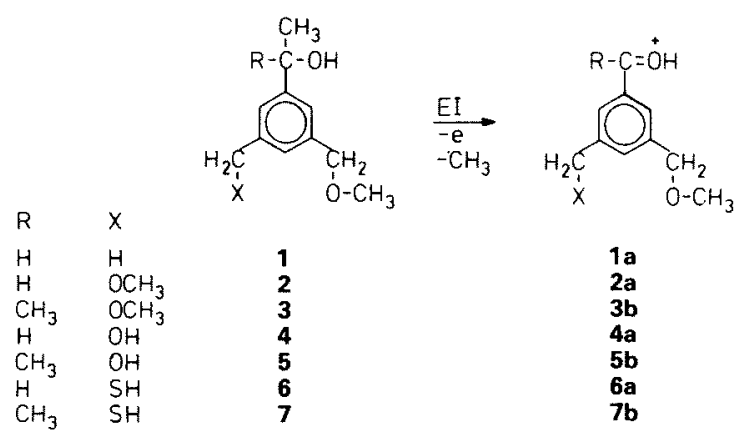

Scheme 2. Generation of protonated benzaldehydes a and protonated acetophenones $\boldsymbol{b}$.

position 3 and 5 by a methoxymethyl group and an additional side chain is the electron impact (EI) induced fragmentation of the corresponding secondary and tertiary benzylalcohols 1-7, as shown in Scheme 2. The fragment ions $\left[\mathrm{M}-\mathrm{CH}_{3}\right]^{+}$corresponding to ' $a$ ' and ' $b$ ' are isolated and investigated in the 2nd FFR by metastable ion techniques. ${ }^{6}$ The two side chains at the 3 and 5-position are in equivalent meta orientations to the protonated carbonyl group.

The reactions induced by proton migrations in metastable ' $a$ ' and ' $b$ ' will be discussed separately for the different side chains in the following sections. It is of interest, however, to examine first the effect of an 'inert' non-polar substituent at position 5 on the already known fragmentations ${ }^{1}$ of a meta-methoxymethylated protonated benzaldehyde ' $a$ '. This comparison is provided in Fig. 1 by the mass-analysed ion kinetic energy (MIKE) spectrum of the protonated benzaldehyde 1a with a methyl group at position 5 . Compared to the ion without this additional methyl substituent ${ }^{1}$ the same fragmentations are observed with similar relative abundances, and the only additional process is the formation of a small amount of $\left[\mathrm{C}_{7} \mathrm{H}_{7}\right]^{+}, m / z 91$, by the elimination of the formyl group and the methoxymethyl side chain. This confirms that the inductive effect of the additional side chains in the other disubstituted protonated benzaldehydes $2 \mathbf{a}, \mathbf{4 a}, \mathbf{6 a}$ and acetophenones $\mathbf{3 b}$, $\mathbf{5 b}, \mathbf{7 b}$ can be neglected, and that the effects observed in these MIKE spectra are due to the presence of the additional functional group of the substituent.
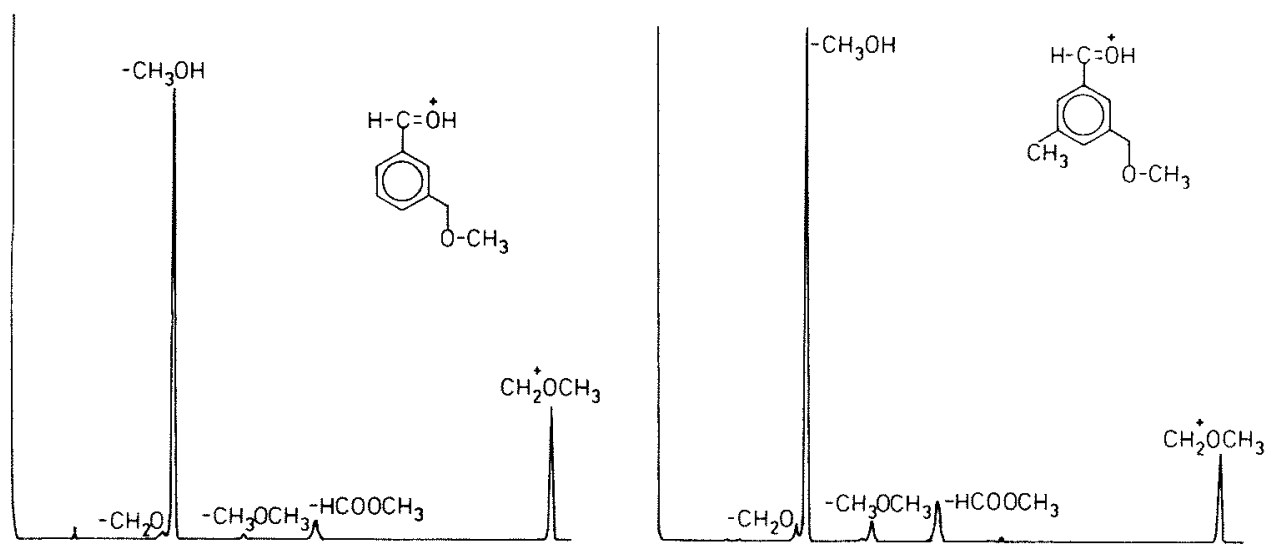

Figure 1. MIKE spectrum of $1 \mathrm{a}$ and protonated meta-methoxymethyl benzaldehyde. 


\section{Protonated bis-3,5-methoxymethyl ketones $2 \mathrm{a}$ and $3 \mathrm{~b}$}

The MIKE spectra of the protonated benzaldehyde 2a and the protonated acetophenone $\mathbf{3 b}$, having a second methoxymethyl side chain in addition to the original one, and those of their deuterated analogues (see Scheme 3) are presented in Table 1.

The main reaction of metastable $2 \mathbf{a}$ and $\mathbf{3 b}$ is the elimination of $\mathrm{CH}_{3} \mathrm{OH}$, but the relative abundance of this process is less than in the case of 1a, in spite of the two methoxymethyl side chains. The data of Table 1 for $2 a\left(D_{3}\right), 2 a\left(D_{3}, D\right)$ and $3 b\left(D_{3}\right)$ prove that both methoxy groups participate in this elimination, and a small sec- ondary isotope effect is observed. The hydrogen atom at the aldehyde group of 2a is not involved at all (see data for $2 \mathrm{a}(\mathrm{D})$ and $2 \mathrm{a}\left(\mathrm{D}_{3}, \mathrm{D}\right)$ ), corroborating earlier results. ${ }^{1}$ In contrast to this, the proton originally at the carbonyl group is lost preferentially with the methanol. The loss of $54 \%$ and $55 \% \mathrm{CH}_{3} \mathrm{OD}$ from $2 \mathrm{a}(\mathrm{OD})$ and $3 \mathrm{~b}(\mathrm{OD})$, respectively, exceeds by far the $25 \%$ expected from a statistical exchange of the migrating deuteron with the three hydrogen atoms at the aromatic ring during a ring-walk ( $\sigma$-route). It has been suggested ${ }^{7}$ that this is due to the 'direct' transfer of a proton across the aromatic ring by a $\pi$-complex. The relative abundance of this $\pi$-route compared to the $\sigma$-route is less than in the

\begin{tabular}{|c|c|c|c|c|c|c|}
\hline & $2 a$ & $2 a(0 D)$ & $2 \mathbf{a}(\mathrm{D})$ & $2 \mathbf{a}\left(\mathrm{D}_{3}\right)$ & $2 \mathbf{a}\left(\mathrm{D}_{3}, \mathrm{OD}\right)$ & $2 a\left(D_{3}, D\right)$ \\
\hline$-\mathrm{CH}_{2} \mathrm{O}$ & 3 & 6 & 4 & 2 & 2 & 3 \\
\hline$-\mathrm{CH}_{3} \mathrm{OH}$ & 61 & 24 & 60 & 36 & 16 & 35 \\
\hline$-\mathrm{CH}_{3} \mathrm{OD}$ & - & 28 & - & - & 18 & - \\
\hline$-\mathrm{CD}_{3} \mathrm{OH}$ & - & - & - & 30 & 12 & 30 \\
\hline$-\mathrm{CD}_{3} \mathrm{OD}$ & - & - & - & - & 15 & - \\
\hline$-\mathrm{CH}_{3} \mathrm{OCH}_{3}$ & 3 & 3 & - & 2 & 2 & - \\
\hline$-\mathrm{CH}_{2} \mathrm{DOCH}_{3}$ & - & - & 3 & - & - & 1 \\
\hline$-\mathrm{CD}_{3} \mathrm{OCH}_{3}$ & - & - & - & 2 & 2 & - \\
\hline$-\mathrm{CD}_{3} \mathrm{OCH}_{2} \mathrm{D}$ & - & - & - & - & - & 1 \\
\hline$-\mathrm{HCOOCH}_{3}$ & 2 & 3 & - & 1 & 2 & - \\
\hline$-\mathrm{DCOOCH}_{3}$ & - & - & 3 & - & - & 1 \\
\hline$-\mathrm{HCOOCD}_{3}$ & - & - & - & 1 & 2 & - \\
\hline$-\mathrm{DCOOCD}_{3}$ & - & - & - & - & - & 1 \\
\hline$-\mathrm{C}_{2} \mathrm{H}_{6} \mathrm{O}_{2}$ & 11 & 7 & 9 & - & - & - \\
\hline$-\mathrm{C}_{2} \mathrm{H}_{5} \mathrm{DO}_{2}$ & - & 9 & - & - & - & - \\
\hline$-\mathrm{C}_{2} \mathrm{H}_{4} \mathrm{D}_{2} \mathrm{O}_{2}$ & - & - & - & 5 & 3 & 6 \\
\hline$-\mathrm{C}_{2} \mathrm{H}_{3} \mathrm{D}_{3} \mathrm{O}_{2}$ & - & - & - & 6 & 7 & 6 \\
\hline$-\mathrm{C}_{2} \mathrm{H}_{2} \mathrm{D}_{4} \mathrm{O}_{2}$ & - & - & - & - & 4 & - \\
\hline$-\mathrm{C}_{3} \mathrm{H}_{8} \mathrm{O}_{2}$ & 9 & 8 & 8 & - & - & - \\
\hline$-\mathrm{C}_{3} \mathrm{H}, \mathrm{DO}_{2}$ & - & - & - & - & - & - \\
\hline$-\mathrm{C}_{3} \mathrm{H}_{6} \mathrm{D}_{2} \mathrm{O}_{2}$ & - & - & - & - & - & -8 \\
\hline$-\mathrm{C}_{3} \mathrm{H}_{5} \mathrm{D}_{3} \mathrm{O}_{2}$ & - & - & - & 8 & 8 & 8 \\
\hline$-\mathrm{C}_{3} \mathrm{H}_{4} \mathrm{D}_{4} \mathrm{O}_{2}$ & - & - & - & - & - & - \\
\hline$\left[\mathrm{C}_{7} \mathrm{H}_{7}\right]^{+}$ & 1 & $\overline{2}$ & $\overline{1}$ & 1 & $\overline{2}$ & $\overline{1}$ \\
\hline $\begin{array}{l}{\left[\mathrm{C}_{7} \mathrm{H}_{6} \mathrm{D}\right]^{+}} \\
{[\mathrm{CH}}\end{array}$ & $\overline{6}$ & $\begin{array}{l}2 \\
6\end{array}$ & $\begin{array}{l}1 \\
6\end{array}$ & $\overline{3}$ & $\begin{array}{l}2 \\
3\end{array}$ & 3 \\
\hline \multirow{2}{*}[\mathrm{CD}_{3}\mathrm{OCH}_{2}]{$^{+}$} & - & - & - & 3 & 3 & 3 \\
\hline & 3b & $3 b(O D)$ & $3 \mathbf{b}\left(\mathrm{D}_{3}\right)$ & & & \\
\hline$-\mathrm{CH}_{2} \mathrm{O}$ & 3 & 3 & 2 & & & \\
\hline$-\mathrm{CH}_{3} \mathrm{OH}$ & 61 & 26 & 33 & & & \\
\hline$-\mathrm{CH}_{3} \mathrm{OD}$ & - & 32 & $\overline{2}$ & & & \\
\hline$-\mathrm{CD}_{3} \mathrm{OH}$ & - & - & 29 & & & \\
\hline$-\mathrm{CH}_{3} \mathrm{OCH}_{3}$ & 1 & 2 & 0.3 & & & \\
\hline$-\mathrm{CH}_{2} \mathrm{DOCH}_{3}$ & - & - & - & & & \\
\hline$-\mathrm{CD}_{3} \mathrm{OCH}_{3}$ & - & - & 0.5 & & & \\
\hline$-\mathrm{CH}_{3} \mathrm{COOCH}_{3}$ & 8 & 8 & 5 & & & \\
\hline$-\mathrm{CH}_{3} \mathrm{COOCD}_{3}$ & - & - & 5 & & & \\
\hline$-\mathrm{C}_{2} \mathrm{H}_{6} \mathrm{O}_{2}$ & $\underline{3}$ & $\begin{array}{l}3 \\
3\end{array}$ & - & & & \\
\hline $\begin{array}{l}-\mathrm{C}_{2} \mathrm{H}_{5} \mathrm{DO}_{2} \\
-\mathrm{C}_{2} \mathrm{H}_{4} \mathrm{D}_{2} \mathrm{O}_{2}\end{array}$ & $\overline{-}$ & - & 2 & & & \\
\hline$-\mathrm{C}_{2} \mathrm{H}_{3} \mathrm{D}_{3} \mathrm{O}_{2}$ & - & - & 2 & & & \\
\hline$-\mathrm{C}_{3} \mathrm{H}_{8} \mathrm{O}_{2}$ & 21 & 21 & - & & & \\
\hline$-\mathrm{C}_{3} \mathrm{H}_{7} \mathrm{DO}_{2}$ & - & $\overline{-}$ & $\overline{-}$ & & & \\
\hline $\begin{array}{l}-\mathrm{C}_{3} \mathrm{H}_{6} \mathrm{D}_{2} \mathrm{O}_{2} \\
-\mathrm{C}_{3} \mathrm{H}_{5} \mathrm{D}_{3} \mathrm{O}_{2}\end{array}$ & - & - & 22 & & & \\
\hline$\left[\mathrm{CH}_{3} \mathrm{OCH}_{2}\right]^{+}$ & 1 & 2 & 1 & & & \\
\hline$\left[\mathrm{CD}_{3} \mathrm{OCH}_{2}\right]^{+}$ & - & - & 1 & & & \\
\hline
\end{tabular}






$2 \mathbf{a}$



$2 \mathbf{a}\left(D_{3}\right)$

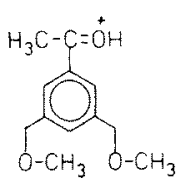

3b



2a $100 \mid$

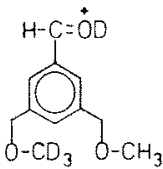

$2 \mathbf{a}\left(\mathrm{D}_{3}, \mathrm{OD}\right)$

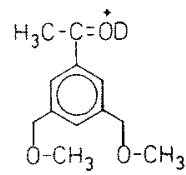

3b $(O D)$



2a(D)



$2 \mathbf{a}\left(\mathrm{D}_{3}, \mathrm{D}\right)$

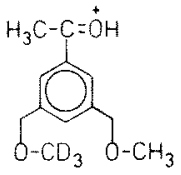

$3 \mathbf{b}\left(\mathrm{O}_{3}\right)$
Scheme 3. Structures of $\mathbf{2 a}$ and $\mathbf{3 b}$ and of deuterated derivatives.

case of the analogous monosubstituted ions, which can be interpreted as an effect of the increased proton affinity of the benzene ring due to the additional substituent. This effect has been studied further with the aid of polymethyl-substituted protonated benzaldehydes and acetophenones and will be discussed in a forthcoming paper. $^{8}$

The losses of formaldehyde, of dimethyl ether and of an ester molecule, respectively, and the formation of ions $\left[\mathrm{H}_{3} \mathrm{COCH}_{2}\right]^{+}$(Table 1) have been observed already for the corresponding monomethoxymethylated ions, and the label distribution observed for the deuterated ions is in perfect agreement with the postulated reaction mechanisms (Scheme 1). Interestingly, two new fragmentations are observed corresponding to the loss of neutral fragments of the elemental composition $\mathrm{C}_{2} \mathrm{H}_{6} \mathrm{O}_{2}$ and $\mathrm{C}_{3} \mathrm{H}_{8} \mathrm{O}_{2}$, respectively. The data from the deuterated ions show clearly (Table 1) that the methoxy groups of both side chains participate in these fragmentations.

An elemental composition of $\mathrm{C}_{2} \mathrm{H}_{6} \mathrm{O}_{2}$ corresponds to the sum of $\mathrm{CH}_{3} \mathrm{OH}$ and $\mathrm{CH}_{2} \mathrm{O}$ as the neutral fragment. In fact, the deuterium distribution for this process is the same as for the elimination of methanol (see 2a(OD), $2 a\left(D_{3}, O D\right)$ and $\left.3 b(O D)\right)$, which identifies this additional reaction as the loss of $\mathrm{CH}_{2} \mathrm{O}$ from the second methoxymethyl group subsequent to the elimination of methanol. The elimination of formaldehyde as the first reaction step is excluded by these data. The former reaction sequence is corroborated further by the MIKE spectrum of a 3-acetyl-5-methoxymethyl benzyl cation, generated independently by loss of $\mathrm{Br}^{*}$ from the molecular ions of 3-bromomethyl-5-methoxymethyl acetophenone, which exhibits an intense signal due to the loss of $\mathrm{CH}_{2} \mathrm{O}^{5}$ Only the losses of $\mathrm{CH}_{3} \mathrm{OH}+\mathrm{CD}_{2} \mathrm{O}$ and $\mathrm{CD}_{3} \mathrm{OH}+\mathrm{CH}_{2} \mathrm{O}$, respectively, are found in the MIKE spectra of $2 \mathbf{a}\left(\mathrm{D}_{3}\right)$ and $3 \mathbf{b}\left(\mathrm{D}_{3}\right)$, proving a transfer of an H(D) atom from the methoxy group onto the remaining part of the ion during the formaldehyde elimination of the second step. A mechanism for this process is depicted in Scheme 4.



Scheme 4. Elimination of $\mathrm{CH}_{3} \mathrm{OH}$ and $\mathrm{CH}_{2} \mathrm{O}$ from 2a and $3 b$.

The fragments of elemental composition $\mathrm{C}_{3} \mathrm{H}_{8} \mathrm{O}_{2}$ also contain both methoxy groups. This follows unequivocally from the complete shift (Table 1) to $\mathrm{C}_{3} \mathrm{H}_{5} \mathrm{D}_{3} \mathrm{O}_{2}$ in the case of $2 \mathrm{a}\left(\mathrm{D}_{3}\right), \mathbf{2 a}\left(\mathrm{D}_{3}, \mathrm{OD}\right), \mathbf{2 a}\left(\mathrm{D}_{3}\right.$, D) and $3 \mathbf{b}\left(\mathrm{D}_{3}\right)$. Neither the proton at the carbonyl group (see $\mathbf{2 a}(\mathrm{OD})$ and $\mathbf{3 b}(\mathrm{OD})$ ) nor the hydrogen atom at the formyl substituent (see $2 \mathbf{a}(\mathrm{D})$ and $2 \mathrm{a}\left(\mathrm{D}_{3}, \mathrm{D}\right)$ ) is included in these fragments. The former result excludes any two-step process with the elimination of methanol as one of the steps; the latter eliminates any reaction sequence with the loss of dimethyl ether as the first step. Thus, the only reasonable fragments for the total loss of $\mathrm{C}_{3} \mathrm{H}_{8} \mathrm{O}_{2}$ are the loss of a complete $\mathrm{CH}_{3} \mathrm{OCH}_{2}$ side chain and of the $\mathrm{CH}_{3} \mathrm{O}$ group from the other substituent. Neither the loss of a $\mathrm{CH}_{3} \mathrm{OCH}_{2}-$ radical nor the loss of a $\mathrm{CH}_{3} \mathrm{O}$ - radical is observed as a single reaction step in the MIKE spectra of $\mathbf{2 a}$ and $\mathbf{3 b}$, but only the combined loss of both fragments. These experimental facts are explained by the mechanism depicted in Scheme 5, corresponding to a fragmentation by an internal ion-neutral reaction within an intermediary complex of the methoxymethyl cation.

The crucial step in this mechanism is the complex formation between the methoxymethyl cation, arising from a protolytic bond cleavage, and a methoxymethylated benzaldehyde or acetophenone. Internal reactions of an analogous complex formed from protonated aromatic ketones carrying only one methoxymethyl side chain have already been observed. ${ }^{1}$ These give rise to the loss of formaldehyde and dimethyl ether, respectively. The complex formation should be assisted by the additional polar side chain in the neutral component and losses of $\mathrm{CH}_{2} \mathrm{O}$ and $\mathrm{CH}_{3} \mathrm{OCH}_{3}$ have indeed been observed in the MIKE spectra of $\mathbf{2 a}$ and $\mathbf{3 b}$ (Table 1). These fragmentations are explained by a migration of the methoxymethyl cation to, and a reaction with, the carbonyl group. In the case of the complex formed from $\mathbf{2 a}$ and $\mathbf{3 b}$, respectively, the methoxymethyl cation migrates also to the remaining methoxymethyl group of the neutral, and a transmethylation followed by the combined loss of formaldehyde and dimethyl ether gives rise to the product ion observed. The same product ion will arise by an attachment of the complete methoxymethyl cation onto the methoxy group and subsequent loss of the dimethyl acetal of formaldehyde, $\mathrm{CH}_{3} \mathrm{OCH}_{2} \mathrm{OCH}_{3}$. Both possibilities cannot be distinguished at the moment. The results of an estimation of the reaction enthalpies for the fragmentations of $\mathbf{2 a}$ and $\mathbf{3 b}$ are shown in Table 2. The elimination of $\mathrm{CH}_{3} \mathrm{OCH}_{2} \mathrm{OCH}_{3}$ needs less energy than the combined loss of $\mathrm{CH}_{3} \mathrm{OCH}_{3}$ and $\mathrm{CH}_{2} \mathrm{O}$ by these data. Further it is of interest to note that the internal reactions of the methoxymethyl cation by transmethylation onto the carbonyl group is 


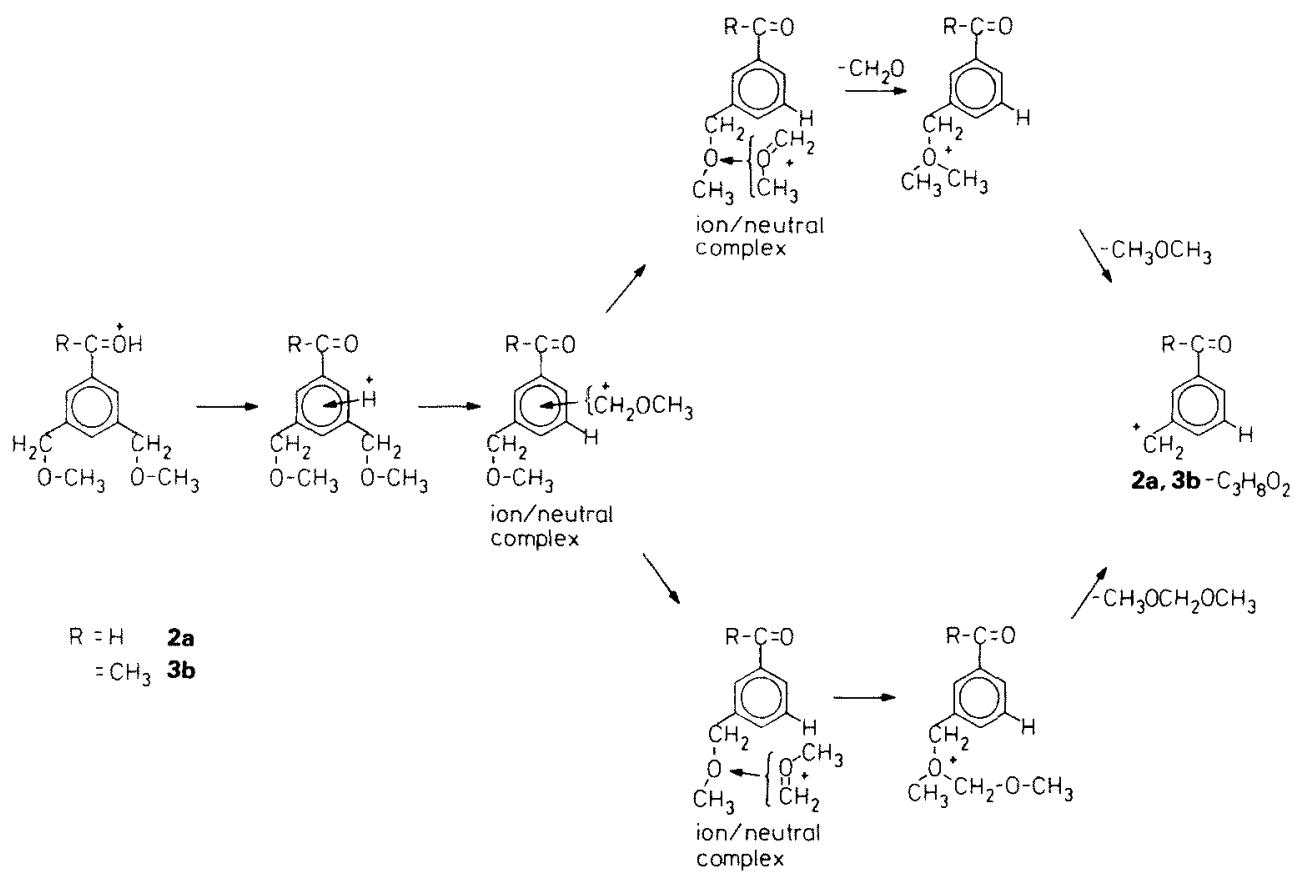

Scheme 5. Loss of $\mathrm{C}_{3} \mathrm{H}_{8} \mathrm{O}_{2}$ from $2 \mathrm{a}$ and $3 \mathbf{b}$.

thermochemically favoured over the internal reaction at the methoxy group, in spite of the abundant signal for the latter process in the MIKE spectra. However, a more reliable calculation of the heats of reaction is needed to establish more firmly this chemoselectivity of the methoxymethyl cation within the ion-neutral complexes.

\section{Protonated 3-hydroxymethyl-5-methoxymethyl ketones $4 a$ and $5 b$}

The MIKE spectra of the protonated benzaldehyde $\mathbf{4 a}$ and the protonated acetophenone 5a, carrying a hydroxymethyl group as the additional side chain, and those of some deuterated derivatives (see Scheme 6) are shown in Table 3.

The elimination of $\mathrm{CH}_{3} \mathrm{OH}$ is again the most important reaction of metastable ions $\mathbf{4 a}$ and $\mathbf{5 b}$ and exceeds by far the loss of $\mathrm{H}_{2} \mathrm{O}$. This correlates with the different proton affinities ${ }^{12}$ of the two side chains, however, and

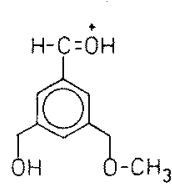

$4 a$

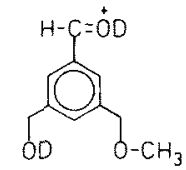

$4 \mathbf{a}(O D)_{2}$

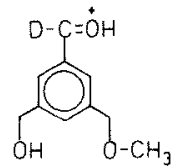

$4 a(D)$
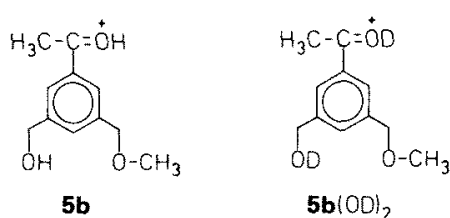

Scheme 6. Structures of $4 a$ and $5 b$ and of their deuterated derivatives. the more basic ether oxygen accepts the migrating proton more easily. Note that for both eliminations some $H / D$ exchange is observed in the OD derivatives, but that the loss of $\mathrm{CH}_{3} \mathrm{OD}$ exceeds the value calculated for a statistical distribution. Thus, the $\pi$-route for a direct proton transfer across the benzene ring operates also in these ions.

The formation of an acylium ion-neutral complex from $\mathbf{4 a}$ and $\mathbf{5 b}$, respectively, and the internal reactions of the acylium ion within these complexes with the hydroxy group and the methoxy group yield $\mathrm{RCOOH}$ and $\mathrm{RCOOCH}_{3}\left(\mathrm{R}=\mathrm{H}, \mathrm{CH}_{3}\right)$, respectively. The loss of $\mathrm{CH}_{3} \mathrm{COOH}$ and $\mathrm{CH}_{3} \mathrm{COOCH}_{3}$ in about equal amounts is observed in the MIKE spectrum of $\mathbf{5 b}$. This indicates an equal probability of the internal acylium reaction with both side chains. Note that in the case of $5 \mathbf{b}(\mathrm{OD})_{2}$ a complete shift to the loss of $\mathrm{CH}_{3} \mathrm{COOD}$ has occurred. In the MIKE spectrum of $\mathbf{4 a}$ only a small peak for the loss of $\mathrm{HCOOCH}_{3}$ is observed, but there is no signal for the loss of $\mathrm{HCOOH}$.

The MIKE spectra of $\mathbf{4 a}$ and of $\mathbf{5 b}$ exhibit a signal for the loss of $\mathrm{C}_{2} \mathrm{H}_{6} \mathrm{O}_{2}$ which corresponds to the combined loss of $\mathrm{CH}_{3} \mathrm{OH}$ and $\mathrm{CH}_{2} \mathrm{O}$ or to the elimination of $\mathrm{HOCH}_{2} \mathrm{OCH}_{3}$. The label distribution between the fragments is very different, however, for the loss of methanol and the loss of fragment(s) $\mathrm{C}_{2} \mathrm{H}_{6} \mathrm{O}_{2}$, respectively, for $4 \mathbf{a}(O D)_{2}$ and $\mathbf{5 b}(\mathrm{OD})_{2}$ (Table 3 ) and excludes any fragmentation mechanism by which the elimination of $\mathrm{CH}_{2} \mathrm{O}$ follows the usual methanol loss. Clearly, the elimination of the fragment(s) $\mathrm{C}_{2} \mathrm{H}_{6} \mathrm{O}_{2}$ from $4 a$ and $5 b$ corresponds to the loss of $\mathrm{CH}_{3} \mathrm{OCH}_{2} \mathrm{OCH}_{3}$ (or $\mathrm{CH}_{3} \mathrm{OCH}_{3}+\mathrm{CH}_{2} \mathrm{O}$ ) from the bis-methoxymethyl-substituted ions $\mathbf{2 a}$ and $\mathbf{3 b}$. A corresponding mechanism is shown in Scheme 7.

The methylene groups of both side chains have not been deuterated separately, so it is not possible at the moment to distinguish between the internal reactions within a complex of a hydroxymethyl cation and a 
Table 2. Estimated heats of reaction $\Delta H_{r}^{\circ}$ for the fragmentations of $2 a^{9-11}$ (heats of formation of $2 a$ and the reaction products in $\mathrm{kJ} \mathrm{mol}^{-1}$ )

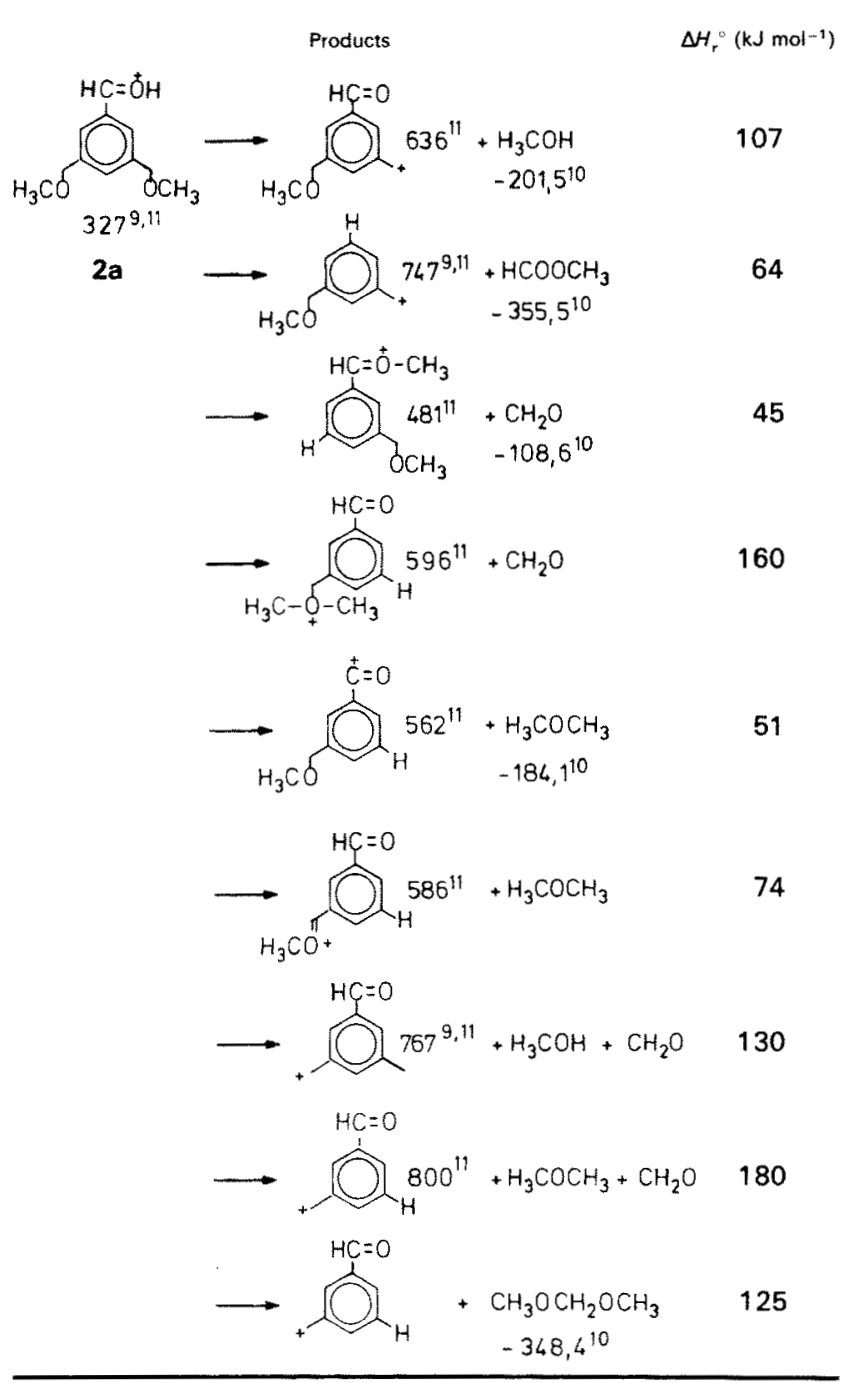

Table 3. MIKE spectrum of $4 \mathrm{a}, 5 \mathrm{~b}$ and deuterated analogues

\begin{tabular}{|c|c|c|c|c|c|}
\hline & $4 a$ & $4 a(O D)_{2}$ & $4 a(D)$ & $5 b$ & $5 b(O D)$ \\
\hline$-\mathrm{CH}_{3}$ & 4 & 5 & 6 & - & - \\
\hline$-\mathrm{H}_{2} \mathrm{O}$ & 3 & - & 3 & 4 & - \\
\hline$-H D O$ & - & -- & - & - & 2 \\
\hline$-\mathrm{D}_{2} \mathrm{O}$ & - & 4 & - & - & 2 \\
\hline$-\mathrm{CH}_{2} \mathrm{O}$ & 5 & 10 & 10 & 24 & 22 \\
\hline$-\mathrm{CH}_{3} \mathrm{OH}$ & 64 & 22 & 58 & 46 & 22 \\
\hline$-\mathrm{CH}_{3} \mathrm{OD}^{\mathrm{a}}$ & - & 40 & 4 & - & 23 \\
\hline$-\mathrm{HCOOH}$ & - & - & - & & \\
\hline$-H C O O D$ & - & - & - & & \\
\hline$-\mathrm{HCOOCH}_{3}$ & 2 & - & - & & \\
\hline$-\mathrm{DCOOCH}_{3}$ & - & - & 2 & & \\
\hline$-\mathrm{CH}_{3} \mathrm{COOH}$ & & & & 5 & - \\
\hline$-\mathrm{CH}_{3} \mathrm{COOD}$ & & & & - & 5 \\
\hline$-\mathrm{CH}_{3} \mathrm{COOCH}_{3}$ & & & & 6 & 7 \\
\hline$-\mathrm{C}_{2} \mathrm{H}_{6} \mathrm{O}_{2}$ & 2 & - & 6 & 16 & - \\
\hline$-\mathrm{C}_{2} \mathrm{H}_{5} \mathrm{DO}_{2}$ & - & 7 & - & - & 17 \\
\hline $\begin{array}{l}-\mathrm{C}_{2} \mathrm{H}_{4} \mathrm{D}_{2} \mathrm{O}_{2} \\
{\left[\mathrm{CH}_{3} \mathrm{OCH}_{2}\right]^{+}}\end{array}$ & $\overline{1}$ & $\overline{2}$ & $\overline{1}$ & $\overline{1}$ & $\overline{1}$ \\
\hline 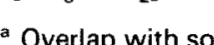 & & & & & \\
\hline
\end{tabular}

complex of a methoxymethyl cation, but the formation of the latter complex would be favoured because of the more stable methoxymethyl cation. Interestingly, the MIKE spectra of both $4 \mathbf{a}$ and $\mathbf{5 b}$, respectively, contain an unusual large peak for the elimination of $\mathrm{CH}_{2} \mathrm{O}$, and this can be attributed to an easy proton transfer to the methoxymethyl side chain within the complex of the hydroxymethyl cation. The subsequent loss of methanol containing specifically the proton originally at the hydroxy group of the hydroxymethyl side chain would also explain the total loss of $\mathrm{C}_{2} \mathrm{H}_{6} \mathrm{O}_{2}$. However, this reaction is more endothermic than the loss of $\mathrm{HOCH}_{2} \mathrm{OCH}_{3}$ by an electrophilic attack of the methoxymethyl cation on the hydroxy group within the ion-neutral complex of this ion. ${ }^{13}$

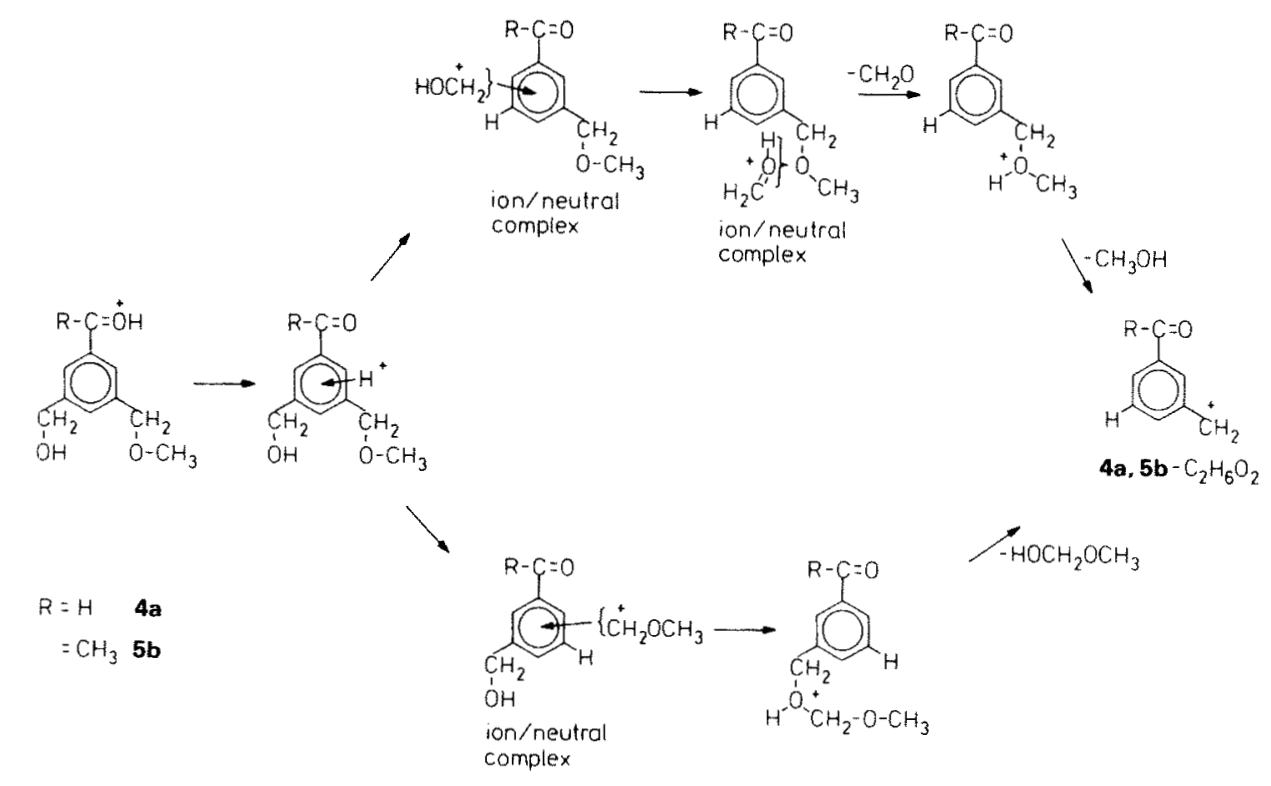

Scheme 7. Loss of $\mathrm{CH}_{2} \mathrm{O}$ and of $\mathrm{C}_{2} \mathrm{H}_{6} \mathrm{O}_{2}$ from $4 \mathrm{a}$ and $\mathbf{5 b}$. 
Protonated 3-mercaptomethyl-5-methoxymethyl ketones $6 a$ and $7 b$

The protonated benzaldehyde $\mathbf{6 a}$ and the protonated acetophenone $7 \mathrm{~b}$ contain a mercaptomethyl side chain with a nucleophilic $S$ atom as the characteristic second side chain. The MIKE spectra of these ions and their deuterated derivates (Scheme 8) are shown in Table 4.

Both MIKE spectra again exhibit a large signal for the loss of a fragment of 32 mass units, which for these ions may also be the loss of an $\mathrm{S}$ atom besides a methanol molecule. This peak is almost completely shifted to the loss of 35 mass units $\left(\mathrm{CD}_{3} \mathrm{OH}\right)$ in the MIKE spectrum of $7 \mathbf{b}\left(\mathrm{D}_{3}\right)$, so that the elimination of $\mathrm{S}$ must be negligible. An H/D exchange is observed again for the elimination of methanol for $6 \mathbf{a}(O D, S D)$ and $7 \mathbf{b}(O D$, $\mathrm{SD})$ showing the migration of the proton by the $\sigma$-route and by the $\pi$-route. The elimination of $\mathrm{H}_{2} \mathrm{~S}$ competes more effectively with the loss of methanol than the loss of $\mathrm{H}_{2} \mathrm{O}$ in the case of ions $4 \mathbf{a}$ and $\mathbf{5 b}$, which is in agreement with the relative proton affinities of an ether group, a mercaptan and an alcohol. ${ }^{12}$ An H/D exchange is also observed in $6 a(O D, S D)$ and $7 b(O D$, $\mathrm{SD}$ ), respectively, which lose a considerable amount of $\mathrm{D}_{2} \mathrm{~S}$ besides $\mathrm{HDS}$, but no $\mathrm{H}_{2} \mathrm{~S}$.

Metastable 6a loses $\mathrm{HCOOCH}_{3}$ and $\mathrm{HCOSH}$, and the mass shifts observed for these processes in the MIKE spectra of the deuterated compounds (Table 4) are in agreement with an internal reaction of an acyl cation with the ether group and the mercapto group, respectively, in an ion-neutral complex. The relative abundances of these processes are small, however. More abundant signals are found in the MIKE spectrum of $7 \mathbf{b}$ for the eliminations of $\mathrm{CH}_{3} \mathrm{COOCH}_{3}$ and $\mathrm{CH}_{3} \mathrm{COSH}$ (Table 4), and the loss of $\mathrm{CH}_{3} \mathrm{COOCH}_{3}$ is distinctly more abundant. This is in contrast to the higher nucleophilicity of mercaptans and sulphides during reactions in condensed phase. ${ }^{14}$

Similarly, the MIKE spectra of $6 \mathbf{a}$ and $7 \mathbf{b}$ contain only small peaks due to the loss $\mathrm{HSCH}_{2} \mathrm{OCH}_{3}$, which arises from an internal reaction of the methoxymethyl cation with the mercapto group in an ion-neutral complex of this ion (Scheme 9). Thus it appears that the $S$ atom of the thiol group is not a favourable reaction centre for the electrophilic carbenium ions in these ionneutral complexes. The only other important reaction of metastable ions $6 \mathrm{a}$ and $7 \mathrm{~b}$ due to the mercaptomethyl

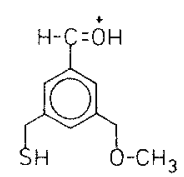

$6 \mathbf{a}$
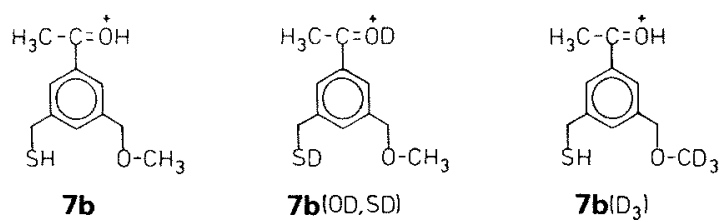

Scheme 8. Structures of $6 a$ and $7 b$ and of some deuterated derivatives.
Table 4. MIKE spectrum of $6 \mathrm{a}, 7 \mathrm{~b}$ and deuterated analogues

\begin{tabular}{|c|c|c|c|c|c|c|}
\hline & $6 a$ & $6 a(O D, S D)$ & $6 a(D)$ & $7 b$ & $7 b(O D, S D)$ & $7 b\left(D_{3}\right)$ \\
\hline$-\mathrm{CH}_{2} \mathrm{O}$ & 1 & 3 & 1 & 7 & 3 & 2 \\
\hline$-\mathrm{CH}_{3} \mathrm{OH}^{\mathrm{a}}$ & 49 & 22 & 51 & 41 & 16 & b \\
\hline$-\mathrm{CH}_{3} \mathrm{OD}$ & - & 28 & - & - & $27^{c}$ & - \\
\hline$-\mathrm{CD}_{3} \mathrm{OH}$ & - & - & - & - & - & 44 \\
\hline$-\mathrm{SH}$ & - & 一 & - & 9 & c & 7 \\
\hline$-S D$ & - & - & - & - & 10 & - \\
\hline$-\mathrm{H}_{2} \mathrm{~S}$ & 29 & - & 30 & 23 & d & 27 \\
\hline$-H D S$ & - & 14 & - & - & 16 & - \\
\hline$-D_{2} S$ & - & 12 & - & - & 9 & 一 \\
\hline$-\mathrm{CH}_{2} \mathrm{~S}$ & 6 & 7 & 7 & 5 & 3 & 6 \\
\hline$-\mathrm{HCOSH}$ & 1 & 一 & - & & & \\
\hline$-\mathrm{HCOSD}$ & - & 1 & - & & & \\
\hline$-\mathrm{DCOSD}$ & - & - & - & & & \\
\hline$-\mathrm{HCOOCH}_{3}$ & 2 & 2 & 2 & & & \\
\hline$-\mathrm{DCOOCH}_{3}$ & - & - & - & & & \\
\hline$-\mathrm{CH}_{3} \mathrm{COSH}$ & & & & 2 & - & - \\
\hline$-\mathrm{CH}_{3} \mathrm{COSD}$ & & & & - & 2 & - \\
\hline$-\mathrm{CH}_{3} \mathrm{COOCH}_{3}$ & & & & 7 & 6 & - \\
\hline$-\mathrm{CH}_{3} \mathrm{COOCD}_{3}$ & & & & - & - & 7 \\
\hline$-\mathrm{C}_{2} \mathrm{H}_{6} \mathrm{OS}$ & 2 & - & 2 & 2 & - & - \\
\hline$-\mathrm{C}_{2} \mathrm{H}_{5}$ DOS & - & 2 & - & - & 2 & - \\
\hline$-\mathrm{C}_{2} \mathrm{H}_{4} \mathrm{D}_{2} \mathrm{OS}$ & - & - & - & - & - & - \\
\hline$-\mathrm{C}_{2} \mathrm{H}_{3} \mathrm{D}_{3} \mathrm{OS}$ & - & 一 & - & - & - & 2 \\
\hline$-\left[\mathrm{CH}_{3} \mathrm{OCH}_{2}\right]^{+}$ & 4 & 6 & 4 & 2 & 2 & 一 \\
\hline$-\left[\mathrm{CD}_{3} \mathrm{OCH}_{2}\right]^{+}$ & - & 一 & - & - & - & 2 \\
\hline \multicolumn{7}{|c|}{$\begin{array}{l}\text { Elimination of } \mathrm{S} \text { is not excluded. } \\
2 \% \text { loss of } 32 \mathrm{u}(\mathrm{S} ?) \\
\text { Overlap }-\mathrm{CH}_{3} \mathrm{OD} /-\mathrm{SH} \text {. } \\
\text { Overlap }-\mathrm{SD} /-\mathrm{H}_{2} \mathrm{~S} \text {. }\end{array}$} \\
\hline
\end{tabular}

side chain, besides the loss of $\mathrm{H}_{2} \mathrm{~S}$, is the elimination of $\mathrm{CH}_{2} \mathrm{~S}$. This can be explained by a proton transfer from the HS group to the methoxy group of the other side chain and subsequent elimination of $\mathrm{CH}_{2} \mathrm{~S}$ in an ionneutral complex of a mercaptomethyl cation, as shown in Scheme 9.

\section{CONCLUSION}

The fragmentation of metastable protonated benzaldehydes ' $a$ ' and acetophenones ' $b$ ', which carry a methoxymethyl side chain and additionally a second methoxymethyl substituent, a hydroxymethyl substituent and a mercaptomethyl substituent, respectively, occurs predominantly by the elimination of $\mathrm{CH}_{3} \mathrm{OH}$, $\mathrm{H}_{2} \mathrm{O}$ and $\mathrm{H}_{2} \mathrm{~S}$, respectively. These eliminations are initiated by a migration of the acidic proton at the carbonyl group onto the functional group of the side chains. The more basic functional group is protonated preferentially and eventually eliminated.

Besides these eliminations, fragmentations mediated by intermediary ion-neutral complexes are observed. These ion-neutral complexes are formed by a protolytic cleavage of the bond to one of the three substituents in an intermediate arenium ion ( $\sigma$-complex). The internal ion-molecule reactions proceed by a migration of the ionic component, directed by the dipoles of the side chains, to the nucleophilic centres of these groups. Besides the elimination of an ester molecule, which has 


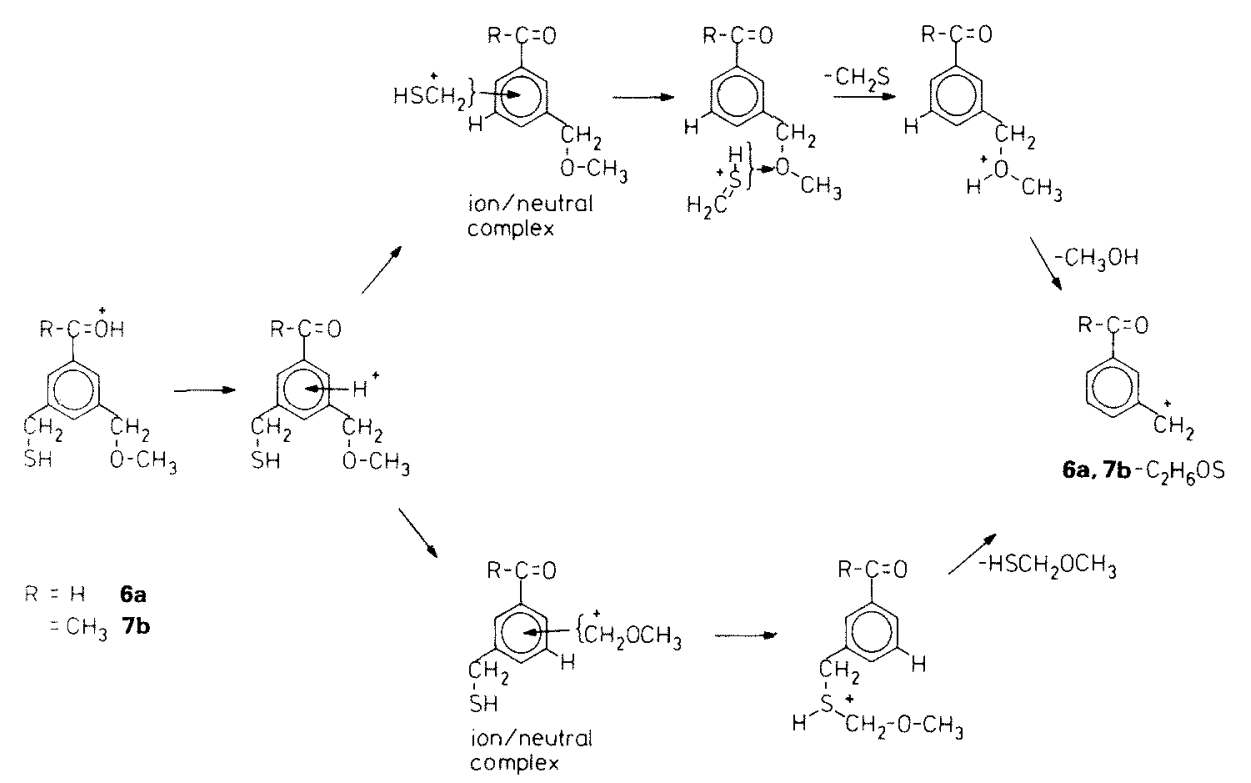

Scheme 9. Losses of $\mathrm{CH}_{2} \mathrm{~S}$ and of $\mathrm{C}_{2} \mathrm{H}_{6} \mathrm{OS}$ from $6 \mathrm{a}$ and 7b.

been observed before the fragmentations of monomethoxymethylated and protonated aromatic ketones ${ }^{1}$ and which arise from an internal reaction of an acylium ion with the methoxy group, the corresponding loss of a carboxylic acid and of a thiocarboxylic acid, respectively, is observed for ions with a hydroxymethyl group and a mercaptomethyl group. Furthermore, the products of internal ion-molecule reactions of a methoxymethyl cation, and of the related ions from the other side chains, have been identified by the aid of deuterated derivatives. The most abundant reaction is an attachment of the electrophile $\left[\mathrm{CH}_{3} \mathrm{OCH}_{2}\right]^{+}$to a nucleophilic methoxy group, a hydroxy group and a mercapto group, respectively, and the subsequent loss of $\mathrm{CH}_{3} \mathrm{OCH}_{2} \mathrm{OCH}_{3}, \mathrm{CH}_{3} \mathrm{OCH}_{2} \mathrm{OH}$ or $\mathrm{CH}_{3} \mathrm{OCH}_{2} \mathrm{SH}$. The competition between these different internal ionmolecule reactions within these intermediary ionneutral complexes appears to be influenced mainly by the differences in the heats of reaction.

\section{EXPERIMENTAL}

\section{Mass spectrometry}

The EI mass spectra of compounds 1-7 were obtained with a MAT 311A mass spectrometer and a MAT SS 200 data system using the following experimental conditions: electron energy $70 \mathrm{eV}$, electron emission current 2 $\mathrm{mA}$, acceleration voltage $3 \mathrm{kV}$, ion source temperature $180^{\circ} \mathrm{C}$, direct sample inlet.

The MIKE and collisional activation (CA) spectra of molecular ions and selected fragment ions were measured using a VG ZAB $2 F$ mass spectrometer and the following conditions: electron energy $70 \mathrm{eV}$, electron trap current $100 \mu \mathrm{A}$, acceleration voltage $6 \mathrm{kV}$, ion source temperature $<200^{\circ} \mathrm{C}$, direct sample inlet at sample temperatures $<60^{\circ} \mathrm{C}$. The ions of interest were focused magnetically into the 2nd FFR and the MIKE spectrum obtained by scanning the ESA voltage. The CA spectra were obtained by the same technique but introducing $\mathrm{He}$ gas into the collision cell of the 2 nd FFR at such a rate that the intensity of the main ion beam was reduced to $50 \%$. The relative intensities given in the table are the mean values of at least three measurements.

\section{Compounds}

The substituted 1-phenyl ethanols 1, 2, 4, 6 and the substituted 2-phenyl propan-2-ols 3, 5, 7 (see Scheme 2) were prepared from the correspondingly substituted acetophenones by reduction with $\mathrm{LiAlH}_{4}$ /ether and by reactions with $\mathrm{CH}_{3} \mathrm{MgI} /$ ether using standard techniques of organic chemistry. ${ }^{5}$ The compounds were purified by column chromatography and characterized by infrared and ${ }^{1} \mathrm{H}$-nuclear magnetic resonance spectroscopy. ${ }^{5}$ 3,5Bis-(bromomethyl) acetophenone was obtained by photobromination of 3,5-dimethyl acetophenone ${ }^{15}$ with $\mathrm{NBS} / \mathrm{CCl}_{4}$, yield $73 \%$. The bis-bromo product was reacted by refluxing with excess methanol and the progress of the reaction was controlled by thin layer chromatography until an optimum yield of 3bromomethyl-5-methoxymethyl acetophenone was obtained. The latter compound and 3,5-bis(methoxymethyl) acetophenone were isolated from the reaction mixture by column chromatography (silica gel Merck $60, \mathrm{CH}_{2} \mathrm{Cl}_{2}$ ). Reaction of 3-bromomethyl-5methoxymethyl acetophenone with thiourea/ $\mathrm{NaOH}$ affords 3-mercaptomethyl-5-methoxymethyl acetophenone (yield $39 \%$ ).

\section{Deuterated derivatives}

The deuterated alcohols 2(OD), $3(\mathrm{OD}), \quad \mathbf{4}(\mathrm{OD})_{2}$, $5(\mathrm{OD})_{2}, 6(\mathrm{OD}, \mathrm{SD})$ and $7(\mathrm{OD}, \mathrm{SD})$ were obtained by exchanging the protons of the hydroxy groups and the mercapto group by treatment with $\mathrm{D}_{2} \mathrm{O}$ in the usual manner. It was difficult to obtain the derivatives with 
two readily exchangeable $D$ atoms in high relative abundances, and the reproducibility of the corresponding MIKE spectra is lower than usual.

The derivatives 2(D), 2(D,$D), 4(D)$ and 6(D) containing a $D$ atom at the carbinol-C atom were prepared by $\mathrm{LiALD}_{4}$ reduction of the appropriate acetophenones in ether.

The derivatives $2\left(D_{3}\right), 3\left(D_{3}\right)$ and $7\left(D_{3}\right)$ were obtained by the reaction of the corresponding bromomethyl derivative with $\mathrm{CD}_{3} \mathrm{OH}$.

\section{REFERENCES}

1. (a) U. Filges and H.-Fr. Grützmacher, in Advances in Mass Spectrometry 1985 , ed. by J. F. J. Todd, Part B, p. 763. Wiley, Chichester (1986); (b) U. Filges and H.-Fr. Grützmacher, Org. Mass Spectrom. 21, 673 (1986); (c) U. Filges and H.-Fr. Grützmacher, Org. Mass Spectrom. 22, 444 (1987); (d) U. Filges and H.-Fr. Grützmacher, Int. J. Mass Spectrom Ion Proc, accepted for publication.

2. T. H. Morton, Tetrahedron 38, 3195 (1982).

3. For a leading review, see D. J. McAdoo, Mass Spectrom. Rev., in press.

4. (a) J. L. Beauchamp and R. C. Dunbar, J. Am. Chem. Soc. 92 1477 (1970); (b) G. Baykut, C. H. Watson, R. R. Weller and J. R. Eyler, J. Am. Chem. Soc. 107, 8036 (1985); (c) R. van Doorn and N. N. M. Nibbering, Org. Mass Spectrom. 13, 527 (1978).

5. G. Thielking, Diplomarbeit, Universität Bielefeld (1987).

6. (a) R. G. Cooks, J. H. Beynon, R. M. Caprioli and G. R. Lester, Metastable Ions, Elsevier, Amsterdam (1973); (b) see also F. W. McLafferty (Ed.), Tandem Mass Spectrometry, Wiley, New York (1983)

7. U. Filges and H. F. Grützmacher, Int. J. Mass Spectrom. Ion Proc., accepted for publication.
8. (a) G. Thielking and Hans-Fr. Grützmacher, Diskussionstagung der AG Massenspektrometrie, Oldenburg (1987): (b) G. Thielking and H.-Fr. Grützmacher, to be published.

9. S. W. Benson, Thermochemical Kinetics, Wiley, New York (1976).

10. J. B. Pedley, R. D. Naylor and S. P. Kirby, Thermochemical Data of Organic Compounds, 2nd edn, Chapman \& Hall, London (1986)

11. Calculated by MNDO; W. Thiel, OCPE 4, 379 (1979).

12. S. G. Lias, J. F. Liebman and R. D. Levin, J. Phys. Chem. Ref. Data 13, 695 (1984).

13. Combined heat of formation of $\mathrm{CH}_{2} \mathrm{O}\left(-108.6 \mathrm{~kJ} \mathrm{~mol}^{-1}\right)$ and methanol $\left(-201.5 \mathrm{~kJ} \mathrm{~mol}^{-1}\right)=-310 \mathrm{~kJ} \mathrm{~mol}^{-1}$ (Ref. 10); heat of formation $\mathrm{HOCH}_{2} \mathrm{OCH}_{3}=-365 \mathrm{~kJ} \mathrm{~mol}^{-1}$ (Ref. 9).

14. Th. H. Lowry and K. Schueller Richardson, Mechanism and Theory in Organic Chemistry, 3rd edn, Harper \& Row, New York (1987).

15. C. R. Hauser and G. A. Reynolds, Org. Synth. Coll. IV, p. 708 (1963). 